\title{
Invivo Anti Trypanosomal Efficacy of Fractions of Crude Methanolic Seed Extract of Adansonia Digitata in Albino Mice
}

\author{
H.M. Ibrahim ${ }^{1 *}$. B.M. Agaie ${ }^{2}$, A.A.Abubakar ${ }^{3}$., B. Saidu ${ }^{1}$, A.I. Jafaru ${ }^{1}$, \\ S.A. Habibullah ${ }^{1}$, Y.S. Baraya ${ }^{4}$ A.A.Raji ${ }^{4}$ \\ ${ }^{I}$ Department of Veterinary Physiology and Biochemistry ${ }^{2}$ Department of Veterinary Pharmacology \\ Toxicology Department of Veterinary Surgery and Radiology ${ }^{4}$ Department of Veterinary Pathology \\ Faculty of Veterinary Medicine, Usman Danfodiyo University Sokoto, Nigeria.
}

\begin{abstract}
Adansonia digitata, a shrub used in traditional medicine for the treatment of cancer was investigated for the treatment of experimental trypanosomiasis. Methanol seed extracts of the seed of Adansonia digitata was investigated for in-vivo anti-trypanosomal activity in albino mice infected with Trypanosoma brucei brucei and treated intraperitoneally with the extracts 24 hours post infection, at doses ranging from $50-500 \mathrm{mg} / \mathrm{kg}$ for 14 days. The parasitaemia in each mouse was monitored including the control group which were treated with the standard drug; Berenil ${ }^{R}$. Seed extracts at dose of $400 \mathrm{mg} / \mathrm{kg}$ showed significant antitrypanosomal activity $(P<0.05)$. Although parasites were not completely cleared from circulation, $67 \%$ of the experimental animals survived for over 43 days. Fraction E obtained from column chromatography of the seed extract cleared parasites completely with no relapse. The treated control (berenil at dose of $3.5 \mathrm{mg} / \mathrm{kg}$ ) showed $100 \%$ survival and parasites were completely cleared. The L.D $D_{50}$ value of the crude seed extract was estimated to be more than $2900 \mathrm{mg} / \mathrm{kg}$. Phytochemical screening of the crude extract of the seed indicated the presence of carbohydrate, glycosides, cardiac glycosides, saponins, steroids and triterpene, flavonoids and alkaloids. The result of this study shows that Adansonia digitata has great potential as anti trypanosomal agent, which could be developed into an alternative drug to complement treatment options for African trypanosomiasis.
\end{abstract}

Key words: Trypanosomiasis, anti-trypansomal, intraperitoneally, parasitaemia, phytochemical screening.

\section{Introduction}

Human African trypanosomiasis (HAT) or sleeping sickness is a severe fly-borne disease caused by protozoan of the species Trypanosoma brucei (T.b.). This disease was first described by European explorers by the late 1800s and early 1900s even if this disease has probably existed in Africa for many centuries [1]. The disease occurs in foci in the tsetse fly (Glossina spp) "belt", a vast geographical region ranging from the Sahara to the Kalahari Desert equivalent to "the combined size of the United States, India and Western Europe" where these flies have their habitat [2]. Three major epidemics of HAT occurred in Africa during the last century, of which the most devastating (which killed millions of persons) occurred from the 1930s to the 1960s [3]. The colonial administrations established mobile teams which systematically screened people in the endemic areas, curing those found with the disease. This initiative resulted in a significant roll back of the disease. In the early 1960s, HAT ceased to be a public health problem, and was no more considered [4]. From the 1970s to the 1990s, favored by dramatic events such as wars and population movements, HAT re-emerged and became an ongoing epidemic. WHO, private partners, and local governments took action, resulting in a significant decrease of the number of new cases reported which, in 2009, which was lower than 10,000 for the first time in 50 years [3].

Despite these encouraging results, HAT is still a considerable burden for life quality and economy in many sub-Saharan Africa countries, where there may be 200 foci and 15-20 million persons at risk [5], as a large number of new infections may remain unreported or undiagnosed because of remote accessibility of many areas of the endemic region and ongoing wars [6]. Besides, it is generally assumed that new epidemics of HAT could occur, originating from these uncontrolled areas where there still are very active foci [7]. HAT affects poor and remote rural populations dependent on agriculture, fishing, or hunting. Until very recently, this disease was receiving very few attention, and health interventions and research and development were inadequate to the need [3]. In the last 50 years, only one drug, eflornithine, has been developed even though a huge amount of knowledge of African trypanosome biology has been accumulated in the meantime [8] . Overall, the current drugs used to cure HAT are expensive, highly toxic, need parenteral administration, and parasites increasing resistance has been observed [8]. Therefore, less toxic, more efficient, easy-to-administer and nonexpensive drugs are urgently needed in the field. WHO and some private partners have been recently multiplying initiatives, offering funding for research activities for this purpose. Some encouraging results have already been 
reported. The research activities have been also aiming at developing new field suitable, easy to-use, and cheap tools to solve the HAT diagnosis, staging, and follow-up issues observed in the field.

\section{Materials and Method}

\section{Plant collection}

Fresh seeds of Adansonia digitata were collected between the months of September and October 2010 in Maiduguri, Borno State capital. The seeds were washed and dried at room temperature. The dried seed sample was then grinded to powdered form and stored in an envelope until required for use.

\section{Animal and parasite}

Albino Mice were purchased from the Department of Pharmacology, Faculty of Pharmacy, Ahmadu Bello University (A.B.U) Zaria, Nigeria. The mice were transported to Federal University of Technology Minna (F.U.T Minna) via road transport and were allowed to acclimatized in environment of Department of Biochemistry Federal University of Technology Minna (F.U.T Minna) for two weeks. The mice were fed with poultry feed (chick mash) purchased from vita feed and water ad libitum. The experiments were conducted in compliance with the internationally accepted principles for laboratory Animals use and care as contained in the Canadian Council on Animal Care (CCAC,1997), guidelines for Animal use.

A stabilized pleomorphic Trypanasoma brucei brucei was obtained from the Nigeria Veterinary Research Institute (NVRI) VOM, Plateau State, Nigeria. The parasites were inoculated into albino mice and transported to Federal University of Technology Minna (F.U.T Minna) Niger State.

\section{Preparation of the Crude Extracts}

The extract was prepared by slight modification of the method described by kiuchi et al. (1978) as carried out by Ogbadoyi, et al. (2007). Seventy grams (70g) of the dried seed powder was sequentially extracted using reflux method in $400 \mathrm{ml}$ hexane, ethylacetate, and methanol respectively. The extraction lasted for two (2) hours in each case. Extracts were filtered hot using muslin cloth, and the solvents were evaporated using steam bath. The dried extract obtained after evaporating the solvent was transferred into a sterile universal bottle and kept in the refrigerator until required for use.

\section{Experimental design}

Blood was collected by cardiac puncture with clean sterilized syringe from an infected Mouse and immediately diluted with physiological isotonic solution to serve as diluent for the inoculation of the parasite. Apparently healthy mice were infected intraperitoeally with $0.02 \mathrm{ml}$ of the inoculum containing trypanosome cells. Infection was monitored at two days interval throughout the study period by microscopic examination of blood samples taken from the tails of infected animals.

In order to determine the activity of the extract, six groups of mice, with each group containing three mice were intraperineally treated with the seed extracts at doses of $50 \mathrm{mg} / \mathrm{kg}, 100 \mathrm{mg} / \mathrm{kg}, 200 \mathrm{mg} / \mathrm{kg}, 300 \mathrm{mg} / \mathrm{kg}$, $400 \mathrm{mg} / \mathrm{kg}$ and $500 \mathrm{mg} / \mathrm{kg}$ body weight. Another group that was not infected also treated with $500 \mathrm{mg} / \mathrm{kg}$ seed extract. The seventh group containing another three mice was infected but not treated while the eight group was infected and treated with the standard drug Berenil at a dose of $3.5 \mathrm{mg} / \mathrm{kg}$ bodyweight intra peritoneally. These last three groups served as controls.

\section{Partial Purification of the Plant Extract}

The crude methanol extract of the seed was partially purified using column chromatograph. Slurry was prepared by shaking one hundred gram (100g) of silica gel (Merck, grade 9385, 230-240 mesh size, 600a, Sigma Alderich, USA) with 200mls Hexane in the ratio 9:1 v/v and then packed in a column of $3 \mathrm{~cm}$ in diameter and $30 \mathrm{~cm}$ long. The silica gel was first activated in the oven for 2 hours at $105^{\circ} \mathrm{C}$ prior to the packing of the column (to eliminate moisture and maintain uniform mash size). Thirty (30) gram of the extract was re dissolved in fifty (50) $\mathrm{ml}$ of Hexane and $20 \mathrm{ml}$ of the activated silica gel was used to absorb the extract. The absorbed extract was left under the fan until is dried. The dried absorbed extract was then introduced into the column. Solvents were then added in increasing order of polarity.

\section{Thin Layer Chromatography (TLC)}

Thin layer chromatography was carried out to allow for pooling together of the 22 eluents using their $\mathrm{Rf}$ numbers as factor for merger of different eluents. The 22 eluents were concentrated and a line was drawn 2-3 $\mathrm{cm}$ from the base of the glass plate (origin) using capillary tubes, a spot was made on the origin for each of the eluents. The solvent to be used (Hexane, ethylacetate) was added into the tank to a depth of about $0.5 \mathrm{~cm}$. The lid (cover) was placed and the tank was allowed to become saturated with the vapour of the solvent. The glass plate was then carefully placed into the tank with the spots on the line (origin) about $1.5-25 \mathrm{~cm}$ above the solvent 
and allowed to develop for 2 hours with the tank properly covered. Movement of eluents 1-15 was achieved with the solvent of Hexane, Ethyl acetate, and Methanol in the ratio of 4:4:1, while solvent system of Ethyl acetate and Methanol in the ratio 3:2 was used for eluents 15-22. The plates were removed from the tank and allowed to dry under fan and then sprayed with $10 \% \mathrm{H}_{2} \mathrm{SO}_{4}$. Combination of eluents with similar Rf values gave rise to six fractions.

\section{Acute Toxicity Studies and $L D_{50}$ Determination for Seed Extract.}

The acute toxicity study was done as described by Lork et al., (1983). Three groups of mice were used, is $\mathrm{A}-\mathrm{C}$ and each group contained three mice. Methanolic seed extract was admistered intra-peritoneally at different doses of $1000 \mathrm{mg} / \mathrm{kg}, 100 \mathrm{~kg} / \mathrm{mg}$ and $10 \mathrm{~kg} / \mathrm{mg}$ body weight respectively.

The second phase of the acute toxicity study involved the use of four groups of mice with each group containing three mice. Methanolic seed extract was administered intra peritoneally at different doses of $2900 \mathrm{mg} / \mathrm{kg}$, $1600 \mathrm{mg} / \mathrm{kg}, 1000 \mathrm{mg} / \mathrm{kg}$, and $600 \mathrm{mg} / \mathrm{kg}$, respectively.

\section{Phytochemical Analysis of the Partially Purified Extract.}

The methanolic seed extract was screened for the presence of saponins, carbohydrates, tannins, terpenes, flavonoids, anthraquinones, alkaloids, steroids, glycosides and resins using simple chemical tests as described by Odebiyi and Sofowara (1982-1986) and Trease and Evans (1989)

\section{Administration of Fraction from Methanol Seed Extract and Monitoring the Course of Parasitemia.}

In order to determine the activity of the fraction obtained from methanol seed extract. Eight groups of mice with each group containing three mice were infected with T.b. brucei and labelled alphabetically as groups A to F. Each group was treated with specific fraction at the dose of $100 \mathrm{mg} / \mathrm{kg}$ body weight, e.g group A was treated with fraction A, group B with fraction B etc. The seventh group containing another three mice was infected but not treated while the eight group was infected and treated with the standard drug Berenil at a dose of $3.5 \mathrm{mg} / \mathrm{kg}$ body weight intraperitoneally. These last two groups served as controls.

\section{Results}

Antitrypanosomal Activity of Fractions from Methanol Extract of A. digitata

Fraction E produced the highest activity against the trypanosome parasites and its activity was comparable $(\mathrm{P}>0.05)$ with that of the positive control treated with Berenil (Figure 1.2).

Also, the antitrypanosomal activities of fraction A, D and F were statistically comparable to Berenil. The infected and untreated group had the highest number of parasites which differed significantly $(\mathrm{P}<0.05)$ from that of the test groups. The mean number of parasites found in mice treated with fraction $\mathrm{B}, \mathrm{C}$ and $\mathrm{F}$ were high and statistically comparable $(\mathrm{P}>0.05)$.

The various fractions (A-F) of the methanolic hot seed extract of $A$. digitata showed some levels of antitrypanosomal activity compared to the untreated control group. There was also the extension of life of the treated groups beyond that of the untreated control.

Fraction $\mathrm{E}$ of the extract cleared the parasites from circulation within 6-14 and 18-20 days of treatment respectively with prolonging survival period of up to 24 days,

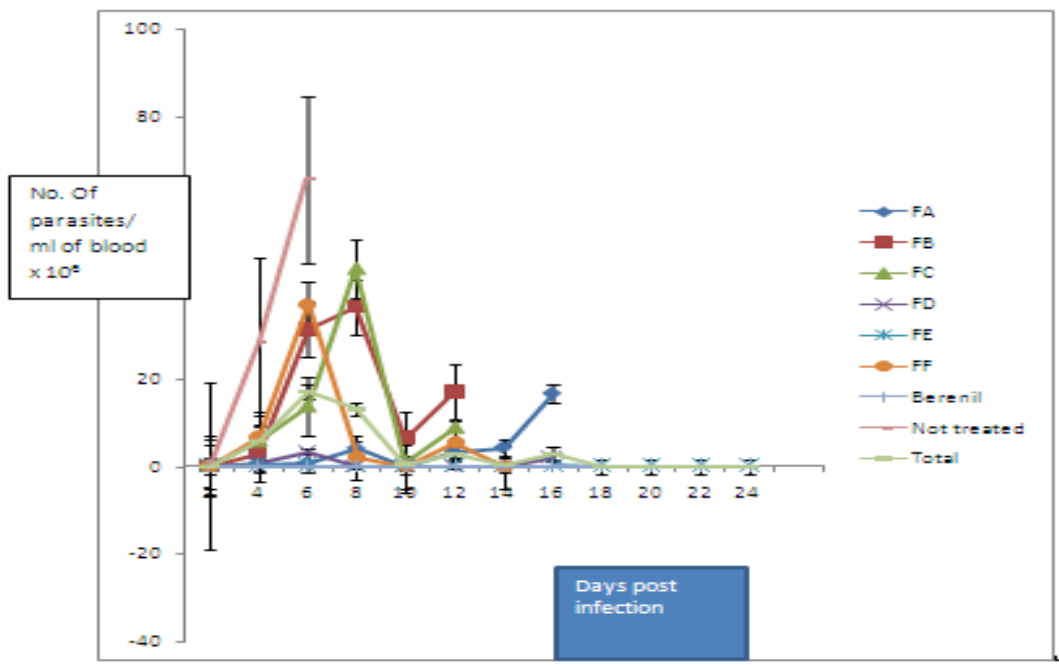

Figure: 1.1 Antitrypanosomal activities of Fractions expressed as mean number of parasites in blood. 


\section{Discussion}

The results obtained in this study show that the methanol hot seed extract of A. digitata exhibited appreciable antitrypanosomal activity compared to the standard drug, berenil, since it was able to prolong the lifespan of the test animals beyond that of the untreated control by 24 days. This observation is similar to that of [9] who reported strong activity of methanolic extracts of Solanum schimperianum and C. tuberculata; [10] also made similar observations for Ximenia Americana.

The mechanism by which the extracts of this plant exert their trypanocidal activity is unknown since the active ingredient(s) were not isolated. However, previous reports indicate that a number of tropical plants contain constituents that have been demonstrated to be clinically efficacious against many protozoal diseases [11]. Similarly, it is known that existing trypanocidal drugs exert their therapeutic action through a variety of mechanisms [12]. [13] reported that many natural products exhibit their trypanocidal activity by virtue of their interference with the redox balance of the parasites acting either on the respiratory chain or on the cellular defenses against oxidative stress. This is because natural products possess structures capable of generating radicals that may cause peroxidative damage to enzymes that are very sensitive to alterations in redox balance. Some agents also act by binding with the kinetoplast DNA of trypanosomes [14]. Different phytochemical constituents might also be responsible for the antitrypanosomal activities [15].

Several studies have reported the presence of phytochemicals such alkaloids in A. digitata [11]. According to [16] antitrypanosomal activity could also be attributed to the presence of alkaloids. The DNA intercalation in combination with protein biosynthesis inhibition is reported to be the mechanism of action responsible for the observed anti-trypanosomal effect of the active alkaloids (Merschjohann et al., 2001). The trypanocidal activity of several flavonoids such as quercetagetin [17]; hispidulin and santin [18] has been previously reported.

Furthermore, the trypanocidal activity of the methanolic seed extract at $100 \mathrm{mg} / \mathrm{kg}-500 \mathrm{mg} / \mathrm{kg}$ concentration was statistically comparable to that of the positive control. Generally, there were fluctuations in the level of parasitaemia of all the treated groups, which were however, kept relatively at very low level. This could be as a result of resistance put forward by the parasites or some limitations on the part of the extract itself such as the inability of the extract to permeate other tissues where the flagellates are known to hide as a way of evading trypanolytic action of drugs [19].

It has been shown in previous studies that different parts of the same plant could show varying levels of antitrypanosomal activity just as extracts of different parts of the same plant [14]; Igwe and Onabanjo, 1989). In this present study the extracts had varying degrees of antitrypanosomal activity based on the solvent used for extraction. Therefore, the statement that a plant extracts is efficacious or not should be taken in the context of the solvent used. In some instances, where extracts obtained by reflux (hot) extraction were compared to those acquired through cold extraction, it was observed that more activity was observed with cold extract, indicating that trypanocidal components of many plants are heat-labile [12]. This may explain why some plants reported to be traditionally useful for treating trypanosomiasis are not active when scientifically evaluated in the past. It may therefore be advisable to use cold rather than hot extraction, where possible, when evaluating the trypanocidal activity, or indeed, other biological activities of medicinal plants.

The seed extracts of A. digitata, at different concentrations used in this study showed considerable trypanocidal activity. This finding is in line with earlier reports [20] that clearly indicated that plants of different families could possess potent trypanocidal activity. In fact, natural products with trypanocidal activity and belonging to a variety of phytochemical classes have been identified [21].

The various extracts of $A$. digitata exhibited mild to moderate antitrypanosomal activity at the different concentrations studied (100-500mg/kg) but did not completely clear the parasite. On the other hand, Berenil had total clearance of parasitaemia from the 2nd day post commencement of treatment without relapse of infection throughout the study. The result of this study further showed that $A$. digitata hot seed extract has potential in the management of African Animal trypanosomiasis. The hot seed extract of this plant has demonstrated some level of antitrypanosomal activity by reducing the parasite levels compared to the untreated control. There was also the extension of life of the treated groups beyond that of the untreated control. However, the fluctuations observed points to limitations in the use of these extracts alone. But, since most traditional practices consist of herbal concoctions from different plants [14], it is possible that in such combined herbal therapy involving A. digitata, the contribution of its extract is either to suppress the parasitemia and allow active principle from other component of the herbal mixture to easily wipe out the residual A. digitata - resistant trypanosomes or that the extract is able to interact and weaken the parasites' membrane thereby enhancing the accessibility of organellespecific active component from other plants in the herbal recipe. 


\section{Conclusion}

This work has demonstrated that $A$. digitata possesses some potential for a chemical lead for a new trypanocidal drug. Based on the above, it can be concluded that the use of A. digitata for management of trypanosomiasis in traditional medicine is scientifically justified.

\section{Acknowledgements}

I wish to express appreciation and gratitude to my beloved wife Amina Abubakar Usman whose diligent help in feeding the animals and perseverance to bring this work to a successful completion. I must also not fail to express my sincere gratitude to her for the assistance she rendered both in courage and kind toward the completion of this work. I wish to extend my gratitude to the laboratory technologists of Usmanu Danfodiyo University for their interest in my future. Their encouragement especially during the difficult moments of this study was very outstanding. I acknowledge all the lecturers in the Department. I also appreciate the support of my colleagues, and others whose names are not mentioned here. Thank you all for your moral support. This acknowledgement cannot be complete without extending my appreciation to the entire management of Usmanu Danfodiyo University for giving me opportunity to undertake this study away from my place of work. Finally I wish to specially thank my family members for their patience and persevearance throughout the struggle to complete this very demanding work. May Allah in His infinite mercy bless you all. Ameen.

\section{References}

[1] G. Hide, History of sleeping sickness in East Africa. Clinical microbiology reviews (1999). 112-125. (12)

[2] R.H. Gooding, Genetic variation in Tsetse flies and implication for trypanosomiasis. Parasitology today. (1992). 92-95 (8)

[3] WHO, African trypanosomiasis (sleeping sickness). Geneva, Switzerland technical report. (2010) 295.

[4] P.P .Simarro, J.Jannin, and P. Cattand, Eliminating Human African trypanosomiasis. Where do we stand and what comes next? Plos medicine. (2008). (2 article e55). (5)

[5] G. Cecchi, M. Paone, and J.R. Franco, Toward atlas of human African trypanosomiasis. Internal journal of Health Geography. (2009). 1-5. (8)

[6] E.M. Fevre, B.V. Wissmann, , S.G. Welburn and P. Lutumba, The burden of human African trypanosomiasis. Plos neglected tropical disease. (2008). (12 article e333). (2)

[7] L. Berrang-ford, J. Laudine, and S. Breau, Conflick and human trypanosomiasis. Social science and medicine.: (2011). 398-407. (72)

[8] M.P. Barrett, Boykin, D.W., Brun, R., and R.R. Tidwell, (2007). Human African trypanosomiasis: Pharmacological re-engagement with a neglected disease. British journal of pharmacology. 152: 1155-1171.

[9] E. Abdel-Sattar, F.M. Harraz, S.M.A. Al-Ansari., S. El-Mekkawy, C. Ichino, H. Kiyohara, K . Otoguro, S. Omura, and H. Yamada, Antiplasmodial and antitrypanosomal activity of plants from the Kingdom of Saudi Arabia. Journal of National Medicine (2009). 232-239. (63)

[10] V.A. Maikai, Antitrypanosomal Activity of Flavonoid Extracted from Ximenia Americana Stem Bark. International Journal of Biology, 3: (2011). 115-121. (1)

[11] A. Le Grand, Anti-infectious Phytotherapy of the tree savannah, Senegal (West Africa) III: A review of the phytochemical substances and antimicrobial activity of 43 species. J. Ethnopharmacol. 25 (1989): 315

[12] S.E. Atawodi, T. Bulus, S. Ibrahim, D.A. Amed, A.J. Nok. M. Mamman, and M. Galadima, In vitro trypanocidal effect of methanolic extract of some Nigerian savannah plants. African Journal of Biotechnology, 2, (2005). 317-321.

[13] S. Sepulveda-Boza, B.KPlant metabolites active against Trypanosoma cruzi. Planta Med. 62. (1996).98-105.

[14] S.E. Atawodi, T. Bulus, S. Ibrahim, D.A. Ameh, A.J. Nok, M. Mamman, and M. Galadima, In vitro trypanocidal effect of methanolic extract of some Nigerian Savannah plants. African Journal of Biotechnol. 2 (2003). 317-321. (9)

[15] K. Asres, F. Bucar, E. Knauder, V. Yardley, H. Kendrick, and S.L. Croft, In vitro antiprotozoal activity of extract and compounds from the stem bark of Combretum molle. : Research 15 (2001). 613-617. (7)

[16] A, Mann M,Gbate A, Nda-Umar, Medicinal and Economic Plants of Nupeland. Bida, Niger State, Nigeria: Jube-Evans Books and Publications; (2003). p. 276.

[17] S, Hoet, F.R. Opperdoes, R. Brun, V. Adjakidjé, J. Quetin-Leclercq. In vitro antitrypanosomal activity of ethnopharmacologically selected Beninese plants. J Ethnopharmacol.91(2004):37-42.

[18] V.P. Sülsen, S.I. Cazorla, F M. Frank, F.C. Redko, C.A. Anesini J.D. Coussio, E.L Malchiodi, V.S. Martino, L.V. Muschietti, Trypanocidal and Leishmanicidal Activities of Flavonoids from Argentine Medicinal Plants. Am J Trop Med Hyg. 77(2007:654-659) (4)

[19] V.C. Anosa, Haematological and Biochemical changes in human and animal trypanosomiasis. Protozoologie, 41 (1988). 65-78. (1).

[20] F. Freiburghaus, R. Kaminsky, M.H.N. Nkuna, and R. Brun, Evaluation of African Medicinals for their in vitro trypanocidal activity. Journal of Ethnopharmacol. 55(1996).: 11-21.

[21] K.H. Hopp, L.V. Cunningham, M.C. Bromel, L.J. Schermester, K.S.K, Wahba, in vitro antitrypanosomal activity of certain alkaloids against Trypanosoma lewisi. Lloydia 39 (1976): 375- 377. 